\title{
ARTIKELEN
}

\section{Weerbaar tegen geweld door aandacht voor gender $^{*}$}

\author{
Martina Althoff, Janine Janssen \& Anne-Marie Slotboom
}

\section{Inleiding}

Meer dan een halve eeuw geleden kwam de term 'gender' in de sociaal wetenschappen op. Met het begrip 'gender' wilde men aantonen dat wat we mannelijk of vrouwelijk vinden mede bepaald wordt door sociale patronen en verwachtingen. Maatschappelijke verwachtingen met betrekking tot (delinquent) gedrag leiden tot stereotiepe voorstellingen. Bepaald gedrag wordt bijvoorbeeld van vrouwen wel en van mannen niet verwacht en geaccepteerd. Gender doelt niet alleen op gedrags- maar ook op identiteitsaspecten van mensen. Gender is namelijk niet op biologische verschillen gebaseerd en geen statisch concept, omdat mensen voortdurend en actief gestalte geven aan hun gender: 'Ideeën en opvattingen over "hoe het hoort" worden voortdurend getoetst. Uit reacties van anderen wordt mensen immers duidelijk of ze zich daadwerkelijk gedragen conform de sociaal geaccepteerde verwachtingen met betrekkingen tot hoe mannen en vrouwen zich gedragen. Bij afwijkingen van dit verwachtingspatroon kan gedrag worden bijgesteld met als gevolg dat een bepaalde norm wordt bevestigd. Het schenden van die norm kan weer leiden tot aanpassingen. Op die manier wordt gender "gedaan". '1

De term 'gender' heeft ook ingang gevonden in politiek en beleid. Zo hebben de Verenigde Naties in 1995 op de vierde World Conference on Women het begrip 'gender mainstreaming' geïntroduceerd, en hanteert bijvoorbeeld de Europese Unie sinds 2004 dit als uitgangspunt voor haar beleid. Het gaat hier om mainstreaming a gender perspective in all policies and programs door de effecten van beleid voor vrouwen respectievelijk mannen te analyseren voordat beslissingen worden genomen. ${ }^{2}$ Een hiermee verbonden veronderstelling is dat beleid geba-

* Dr. Martina Althoff is universitair hoofddocent bij de vakgroep Strafrecht en Criminologie aan de Rijksuniversiteit Groningen. Prof. dr. Janine Janssen is hoofd onderzoek van het Landelijk Expertise Centrum Eer Gerelateerd Geweld van de Nationale Politie, lector Veiligheid in Afhankelijkheidsrelaties aan Avans Hogeschool, bijzonder hoogleraar Rechtsantropologie aan de Open Universiteit en tevens voorzitter van de redactie van PROCES. Dr. Anne-Marie Slotboom is universitair hoofddocent bij de vakgroep Strafrecht en Criminologie aan de Vrije Universiteit.

1 M. Althoff \& J. Janssen, 'Wat heeft het allemaal om het lijf? Over het belang van het begrip gender', Justitiële Verkenningen 2013, 5, p. 15.

2 United Nations, The United Nations Fourth World Conference on Women, Platform for Action. Women in Power and Decision-Making 189, Beijing, september 1995, www.un.org/women-watch/ daw/beijing/platform/decision.htm. 
seerd is op verschillende ideeën en verwachtingen ten aanzien van wat voor mannen en vrouwen relevant is. Daaruit volgt dat dat beleid voor mannen en vrouwen bedoeld of onbedoeld anders kan uitpakken. Een dergelijke gendersensitiviteit wil onbedoelde discriminatie en ongelijkheid voorkomen. Het is in feite een pleidooi voor maatwerk. Ook bij de aanpak van geweld speelt het begrip 'gender' inmiddels een belangrijke rol. In deze bijdrage aan het themanummer over weerbaarheid bij professionals vragen wij ons af waarom de aandacht voor gender zo belangrijk is bij de vergroting van de weerbaarheid van de professionals die betrokken zijn bij de aanpak van geweld. Onder weerbaarheid verstaan wij bij professionals dat zij in staat zijn eigen grenzen te onderkennen en te bewaken en daarnaast niet onzeker worden van tegenslag of moeilijkheden. ${ }^{3}$ Waarom en wat moeten professionals in de veiligheidszorg weten over de relatie tussen geweld en gender? Voordat we aan die vraag toekomen, staan wij stil bij de relatie tussen gender en geweld en de belangrijkste inzichten die criminologen het werken met dit concept heeft gebracht. Ook staan wij kort stil bij de doorwerking van dit begrip in de aanpak van geweld. Tot slot beantwoorden wij de hoofdvraag.

\section{Gender en geweld}

\section{Criminologen en gender}

In de criminologie is de opkomst van het begrip 'gender' nauw verbonden met de opkomst van het feminisme en feministische kritiek in de jaren zestig en zeventig van de vorige eeuw. Er werd namelijk weinig geschreven door vrouwen en/of over de criminaliteit van vrouwen. ${ }^{4}$ Die kritiek werd gevoed door een toegenomen belangstelling voor etiologische theorieën ter verklaring van verschillen in criminaliteit tussen mannen en vrouwen, én voor theorieën uit wat toen nog 'vrouwenstudies' heette, gericht op de sociale relaties tussen mannen en vrouwen, alsmede de introductie van het begrip 'gender' ${ }^{5}$ Criminologen gingen onder meer onderzoek doen naar de criminaliteit van vrouwen, processen van criminalisering van vrouwen en de wijze waarop vrouwen in het kader van strafrechtspleging door politie en justitie werden bejegend. Het gebruik van het begrip 'gender' hielp criminologen belangrijke blinde vlekken op dit onderzoeksgebied te verkennen. In dit verband kan gedacht worden aan tot dan toe weinig gestelde vragen als: Hoe komt het dat in de geregistreerde criminaliteit het aandeel van vrouwen zo klein is? Maakt het strafrecht in behandeling verschil tussen mannen en vrouwen? ${ }^{6}$

3 E. Hooghiemstra \& L. Verharen, 'Professionals in een veranderd speelveld: van onwennigheid naar weerbaarheid', Jeugdbeleid 2015, 4, p. 173-179.

4 F. Heidensoh, 'The deviance of woman', British Journal of Sociology 1968, herdrukt in 2010, p. 111-126; C. Smart, Women, Crime and Criminology, Londen: Routledge, Kegan \& Paul 1976.

5 K. Daly, 'Feminist criminologies', in: E. Mc Laughlin \& J. Muncie (red.), The Sage Dictionary of Criminology, Londen: Thousand Oaks 2012, p. 119-121.

6 D.J. Korf, M. Althoff \& E. Enhus, 'Sneeuwwitje en de machoman. Sekse en gender in de (Nederlandstalige) criminologie', Tijdschrift voor Criminologie 2010, 4, p. 335-350. 


\section{Geen symmetrie in geweldservaringen}

De invoering van gender in de criminologie heeft tot het inzicht geleid dat geweldservaringen tussen mannen en vrouwen variëren. Dat bleek onlangs in het debat over \#MeToo ${ }^{7}$ en meer recent ook weer uit een synthesestudie van verschillende prevalentiestudies naar onder meer huiselijk geweld in Nederland. De prevalentieschattingen van huiselijk geweld hebben uitsluitend betrekking op slachtofferschap van fysiek en seksueel geweld onder de Nederlandse bevolking van 18 jaar en ouder. Uit het onderzoek blijkt dat ongeveer één op de twintig $(5,5 \%)$ volwassenen in een periode van vijf jaar naar eigen zeggen wel eens met een voorval van fysiek en/of seksueel geweld in huiselijke kring te maken heeft gehad. Het gaat om $6,2 \%$ van de vrouwen en $4,7 \%$ van de mannen. Dit zijn in totaal circa 747.000 mensen van 18 jaar of ouder. Zij zijn in de genoemde periode van vijf jaar slachtoffer geweest van minstens één incident dat werd gepleegd door iemand uit de brede huiselijke kring: van partner, ex-partner, andere gezins- en familieleden tot huisvrienden. Bij een derde (34\%) van deze mensen bleef het bij een eenmalig incident. Bij 41\% kwam enkele malen een geweldsvoorval voor. Bijna $20 \%$ van de slachtoffers heeft structureel fysiek en/of seksueel huiselijk geweld meegemaakt; dat wil zeggen geweld dat maandelijks, wekelijks of dagelijks voorkwam. Het gaat hier om circa 97.000 vrouwen en circa 27.000 mannen. Hoewel op het eerste gezicht de prevalentiecijfers voor mannen en vrouwen dicht bij elkaar lijken te liggen, worden vrouwen dus wel vaker met meer structureel geweld geconfronteerd. $^{8}$

Als het om slachtoffers van geweld in brede zin gaat, dan zijn cijfers over mannen en vrouwen afzonderlijk moeilijker te vinden. Zo wordt in de veiligheidsmonitor van het ministerie van Justitie en het Centraal Bureau voor de Statistiek (CBS ${ }^{9}$ wel gerapporteerd over slachtofferschap naar leeftijd, maar niet naar sekse. Het CBS rapporteert echter op zijn website ${ }^{10}$ dat in 2017 2,5\% van de mannen en $1,7 \%$ van de vrouwen slachtoffer werd van één of meer geweldsdelicten. Mannen zijn dus iets vaker slachtoffer van geweld in brede zin. Het gaat bij mannen dan vaker om slachtofferschap van geweld in de publieke ruimte. Kortom, er is geen symmetrie in geweldservaringen van mannen en vrouwen.

\section{Blinde vlekken: klasse en etniciteit}

Voordat wij hier verder inzomen op de genoemde asymmetrie lijkt het ons belangrijk te beklemtonen dat naast gender ook andere factoren de asymmetrie mede bepalen. De meest bekende en dominante factoren zijn sociale klasse en etnische achtergrond. Al deze factoren beïnvloeden en versterken elkaar. In de internationale literatuur wordt hier gesproken over intersectionality. Niet altijd staat namelijk gender op de voorgrond van het gedrag. En specifieke geweldservaringen zijn deels beter te begrijpen door naar de context van deze factoren te kij-

7 J. Janssen, 'Eén jaar na \#MeToo: hoe nu verder? Een blik vanuit een criminologisch perspectief', Tijdschrift voor Seksuologie 2018, p. 42-3.

8 A. ten Boom \& K. Wittebrood, De prevalentie van huiselijk geweld en kindermishandeling in Nederland, Den Haag: WODC 2019.

9 Veiligheidsmonitor 2017, CBS.

10 www.cbs.nl/nl-nl/nieuws/2018/51/minder-vrouwen-dan-mannen-slachtoffer-van-geweld. 
ken. Bijvoorbeeld de geweldpleging van jonge mannen met een bepaalde sociaaleconomische positie in grote steden. ${ }^{11}$ Leeftijd en klasse zijn hier bepalend voor hun geweldservaringen als daders én slachtoffers.

\section{Blinde vlekken: vrouwelijke daders en mannelijke slachtoffers}

De belangrijke constatering dat mannen en vrouwen niet in dezelfde mate gewelddadige ervaringen opdoen, wil echter niet zeggen dat het nooit voorkomt dat er vrouwelijke daders zijn en/of mannelijke slachtoffers. In onderzoek naar huiselijk geweld varieert het aantal vrouwelijke daders, afhankelijk van de bron die men gebruikt. ${ }^{12}$ Op basis van zelfrapportage is het aantal vrouwelijke daders veel hoger dan op basis van politiecijfers. Schattingen van huiselijk geweld, geregistreerd in de Basisvoorziening Handhaving (BHV) van de politie, laten zien dat $78 \%$ van de verdachten man is en $22 \%$ vrouw. ${ }^{13}$ Ook het aantal mannelijke en vrouwelijke verdachten van geweld en seksuele misdrijven tezamen (zowel huiselijk geweld als geweld in de publieke ruimte) loopt sterk uiteen. In 2017 bleek van het totale aantal verdachten $86,7 \%$ man en $13,0 \%$ vrouw te zijn. ${ }^{14}$ Ondanks het feit dat er dus wel degelijk sprake is van vrouwelijk daderschap, lijken we vooral oog te hebben voor mannelijke daders en minder voor mannelijke slachtoffers. Deels is dat natuurlijk te verklaren door overrepresentatie van mannelijke plegers, maar dat verklaart niet alles. Hier komen ook genderspecifieke normen en waarden tot uitdrukking.

Zo is het voor mannen niet altijd makkelijk om slachtofferschap te claimen. ${ }^{15}$ Dat is minder 'normaal' dan geweldpleging door jongens of jonge mannen. Bijvoorbeeld op straat rondhangen, stoer zijn en zich fysiek tonen of geweld gebruiken wordt bij hen als normaal en zelfs als natuurlijk beschouwd. Op deze manier wordt ook mannelijkheid toegeschreven; het is typisch iets van mannen, zo wordt geredeneerd. Dit valt op als incidenten bekend worden waarbij meisjes betrokken zijn, bijvoorbeeld in vechtpartijen op straat. Geweld door meisjes wordt vaak gezien als atypisch, in feite als een niet te begrijpen fenomeen. Bovendien worden vrouwen die geweld plegen eerder als slachtoffer beschouwd. Achterliggende gedachte is dan dat deze vrouwen pas gewelddadig werden nadat ze slachtoffer zijn geworden van seksueel misbruik of huiselijk geweld en dus minder (pro)actief, maar meer reactief geweld plegen. Op deze manier wordt dan ook vrouwelijkheid toegeschreven. Uit onderzoek blijkt inderdaad dat mishandeling en seksueel misbruik in de kindertijd voorspellend kunnen zijn voor het plegen

11 M. Althoff, J. Janssen \& M. Scheepmaker, 'Voorwoord', Justitiële Verkenningen 2013, 5, p. 5.

12 L.M.van der Knaap \& S. Bogaerts. 'Mannen en vrouwen als plegers van huiselijk geweld', Justitiele Verkenningen 2010, 8, p. 46-59.

13 P.G. van der Heijden, M. Cruyff \& G. van Gils, Schattingen van de omvang van huiselijk geweld in Nederland, Utrecht: Universiteit Utrecht 2014.

14 S.N. Kalidien, Criminaliteit en rechtshandhaving 2017: Ontwikkelingen en samenhangen,(reeks Onderzoek en beleid), Den Haag: WODC 2018.

15 Zie bijv. J. Janssen \& R. Sanberg, 'Als de nood aan de man komt. Slachtofferschap van mannen bij eergerelateerd geweld', Justitiële Verkenningen 2013, 5, p. 61-80. 
van geweld door vrouwen. ${ }^{16}$ Echter, ook jongens die mishandeld zijn in hun jeugd hebben een grotere kans om later geweld te gebruiken. ${ }^{17}$ Daarnaast laten meisjes en vrouwen gewelddadig gedrag ook nog op een andere manier zien. Zij gebruiken minder fysieke, maar meer sociale, indirecte agressie (denk aan roddelen, uitlachen, buitensluiten). Ook blijken zij bij partnergeweld minder ernstig letsel te veroorzaken en laten ze ook veel minder seksueel agressief gedrag zien dan mannen. ${ }^{18}$ Dit neemt echter niet weg dat sommige vrouwen ook ernstig fysiek geweld plegen.

\section{Voorbij het stereotiepe beeld van mannen als dader en vrouwen als slachtoffer}

Uit onderzoek blijkt dat geweld dat is gepleegd door meisjes en jonge vrouwen vaak neergezet wordt als twee extremen. Aan de ene kant worden gewelddadige meisjes gezien als gevaarlijk, impulsief en onvoorspelbaar, bij wie geweld gezien wordt als het resultaat van psychische problematiek. Aan de andere kant worden gewelddadige meisjes beschreven als koud, berekenend en manipulatief. Een vergelijkbaar patroon kunnen we vinden als we naar slachtofferschap kijken. Als verklaring voor seksueel misbruik van meisjes zijn twee verhalen beschikbaar: het passieve seksueel onschuldig slachtoffer dat toen niet weerbaar was, of het juist niet passieve en seksueel niet onschuldige meisje dat verantwoordelijk en schuldig is voor het misbruik, dus geen echt slachtoffer is: 'The women who, as a child, was not, for example, sexually innocent or lacking agency (albeit whose agency was limited) is left without a story. ${ }^{19}$

Om geweld of agressie goed te kunnen begrijpen, of het nu door mannen of vrouwen wordt gepleegd, is de context waarin geweld plaatsvindt net zo van belang als de betekenis die door de betrokkenen wordt gegeven aan geweld. Als gevraagd wordt hoe meisjes zelf hun eigen gewelddadige gedrag beschrijven, worden uiteenlopende beschrijvingen gegeven, waarbij het woord agressie of geweld nauwelijks gebruikt wordt en veel verteld wordt over verbale of relationele agressie. ${ }^{20}$ Uit onderzoek naar geweld plegende jonge vrouwen blijkt ook dat het plegen van geweld een bewuste keuze kan zijn en een actieve reactie is om te kunnen overleven en om voor zichzelf op te komen; het kan met andere woorden ook een overlevingsstrategie zijn, die voor zelfrespect zorgt in de onveilige context waarin zij bijvoorbeeld zijn opgegroeid. Geweld kan ook een resource zijn om macht te demonstreren en de eigen ondergeschikte sociale positie te verbeteren of om zich te kunnen handhaven in als vernederend ervaren situaties. Het risico op seksueel

16 N. Trauffer \& C.S. Widom, 'Child abuse and neglect, and psychiatric disorders in nonviolent and violent female offenders', Violence and gender 2017, 4, p. 137-143.

17 M.S. Tisak e.a., 'Relations among victimization, witnessing, and perpetration of aggression: impact of gender among youth offenders', Journal of interpersonal violence 2016, p. 1-23.

18 T.F. Denson e.a., 'Aggression in women: Behavior, brain, and hormones', Frontiers in behavioral neuroscience 2018, 12, p. 1-20.

19 J. Woodiwiss, 'Challenges for Feminist Research: Contested Stories, Dominant Narratives and Narrative Frameworks', in: J. Woodiwiss e.a. (red.), Feminist Narrative Research 2017, p. 23, DOI 10.1057/978-1-137-48568-7_2.

20 M.J. Burman, J.A. Brown \& S.A. Batchelor, “Taking it to heart”: girls and the meanings of violence', in: E.A. Stanko (red.), The meaning of violence, Londen: Routledge 2003, p. 71-89. 
geweld neemt in de adolescentie toe, dat geldt voor jonge mannen én vrouwen. Adolescentie is een levensfase die gekarakteriseerd is door conflicten binnen het gezin, maar ook binnen de leeftijdsgroepen. Autonomie en onafhankelijkheid hebben hier voor de betrokkenen veel betekenis. Geweld kan dan ook een vorm van handelingsvermogen zijn om de eigen weerbaarheid te verhogen. ${ }^{21}$

De betekenis die de betrokkenen zelf aan hun geweldpleging ontlenen, verschilt dus duidelijk van de voornoemde genderstereotiepe toeschrijvingen. En het maakt nog weer eens duidelijk dat onze waarneming en al onze observaties 'gendered' zijn en tot verschillende sociale reacties leiden. Niet alleen het geweldsfenomeen is 'gendered', maar ook de beelden van daders en slachtoffers zijn dat: dus niet alleen daderschap, maar ook slachtofferschap is 'gendered'. Samenvattend kan worden gesteld dat door slachtofferschap bij vrouwen en meisjes centraal te stellen, ook als het gaat om hun daderschap, de indruk wordt gewekt dat 'women have only been victims (...) [and] cannot be effective social agents on behalf of themselves or others'. ${ }^{22}$ Tegelijkertijd wordt daarbij slachtofferschap van mannelijke daders genegeerd, wat tot gevolg heeft dat ook de stereotypen versterkt worden dat mannen niet getraumatiseerd kunnen zijn door seksueel misbruik. Anders gezegd, hetzelfde gedrag wordt per gender verschillend beoordeeld en geïnterpreteerd. We kunnen ons niet voorstellen dat dit gegeven geen invloed heeft op de aanpak van geweld.

\section{Politiek, beleid en aanpak van geweld}

Het systematisch toepassen van een genderperspectief heeft consequenties voor politiek, beleid en aanpak van geweldsproblematiek. Om met het laatste te beginnen: genderspecifieke hulpverlening kennen we in Nederland al vanaf eind jaren zestig van de vorige eeuw. Denk in dit verband bijvoorbeeld aan Blijf van mijn Lijf of de Vereniging tegen Kindermishandeling. Deze vrouwenhulpverlening leerde vrouwen hun ervaring in een breder maatschappelijk perspectief te plaatsen. Zo werd de hulpverlening vaak gecombineerd met maatschappelijke actie en belangbehartiging in de strijd tegen seksueel geweld. In het verlengde hiervan en van de discussie over gender ontstond in de jaren tachtig de mannenhulpverlening. Beide vormen van hulpverlening hebben van meet af aan aandacht gevraagd voor maatschappelijke verhoudingen en de manier waarop gender in de maatschappelijke context tot uiting komt. De vrouwenhulpverlening heeft altijd veel aandacht besteed aan machtsverhoudingen tussen mannen en vrouwen en aan de verbetering van de maatschappelijke positie van vrouwen. In de mannenhulpverlening is veel aandacht geweest voor de prijs die mannen betalen voor hun maatschappelijke positie in termen van gezondheid en (emotioneel) isolement. Sinds de jaren

21 S. Batchelor, "Prove me the bam!": Victimization and agency in the lives of young women who commit violent offences', Probation Journal 2005, 52, p. 358-375; M. Althoff, 'Multiple identities and crime: A study of Antillean women and girls in the Netherlands', European Journal of Criminology 2013, 4, p. 394-407; S. Silkenbeumer, Biografische Entwürfe und Weiblichkeitskonzepte aggressiver Mädchen und junger Frauen, Münster 2007.

22 S.G. Harding, Feminism and methodology: Social science issues, Indiana University Press 1987. 
negentig van de vorige eeuw zijn beide vormen van hulpverlening meer naar elkaar toegegroeid. ${ }^{23}$ Desalniettemin leert de praktijk dat in de welzijnssector met name vrouwen de professionals zijn. ${ }^{24}$ Wat voor effecten dit heeft op de hulpverlening, weten we (nog) niet. Hier ligt een belangrijk onderzoeksgebied open. Een vraag die daarnaast opdoemt, is of mannen en vrouwen in de hulpverlening anders willen en moeten worden bejegend of, anders gezegd: hoe kunnen professionals weerbaar zijn tegenover genderverhoudingen? ${ }^{25}$ Hoe blijven zij overeind bij de aanpak van geweldsproblematiek? Op basis van een gendertheoretisch perspectief kunnen wij immers veronderstellen dat over de invulling van gendernormen door de betrokkenen bij geweld - daders, slachtoffers én professionals - met elkaar wordt onderhandeld, dus wordt 'gedaan', en dat dit wel een belangrijke invloed zal hebben op het succes van de hulpverlening. ${ }^{26}$

Beleid voor daders van geweld vanuit een genderperspectief kennen we in Nederland eigenlijk niet of nauwelijks. Wel op het gebied van risicotaxatie van ernstig geweld, maar niet op het gebied van interventies. Naast alle bestaande risicotaxatie-instrumenten om het risico op ernstig geweld in te schatten is in Nederland een instrument ontwikkeld speciaal voor vrouwelijke daders met oog voor andere risicodomeinen dan bekend bij mannen. ${ }^{27}$ Echter, van alle erkende interventies die ontwikkeld zijn om geweld te reduceren is er geen enkel specifiek programma ontwikkeld voor vrouwen, en de effectiviteit van de interventies is ook niet onderzocht bij vrouwen. Een overzicht van Nederlandse en Europese literatuur naar de preventie van intergenerationeel geweld laat ook zien dat er op het gebied van huiselijk geweld in Nederland weinig sprake is van gendersensitief beleid waarin echt sprake is van oog voor genderbepaalde patronen die van invloed kunnen zijn op een interventie. ${ }^{28}$ In de internationale politieke fora wordt vaak gesproken over 'geweld tegen vrouwen' en niet over geweld door vrouwen. Dit zien we ook terug in het beleid van de Verenigde Naties en de Europese Unie. Een goed voorbeeld is de Conventie van Istanbul, die is gebaseerd op het inzicht dat geweld tegen vrouwen een vorm van gendergerelateerd geweld is dat wordt gepleegd tegen vrouwen omdat zij vrouwen zijn. ${ }^{29}$ Van de overheid wordt ver-

N. van Oosten, I. van der Vlugt \& L. Brants, Seksespecifieke hulpverlening, Bussum: Uitgeverij Coutinho 2009.

24 Zie voor meer achtergrondinformatie: Arbeid in Zorg en Welzijn, Integrerend Jaarrapport: Stand van zaken en vooruitblik voor de sector Zorgen, de sector Welzijn en Maatschappelijke Dienstverlening, Jeugdzorg en Kinderopvang, Zoetermeer: Panteia 2014; M. Aoulad Hadj, R. Straver \& J. Janssen, 'Wat hebben mannen nodig? Een verkenning naar het aanbod van mannenhulpverlening, PROCES 2017, 3, p. 249-256.

25 Aoulad Hadj, Straver \& Janssen 2017.

26 Zie hier als voorbeeld het onderzoek naar drugsbehandeling in detentie: T. Kolind \& J. Bjonness "The right way to be a woman": Negotiating femininity in a prison-based drug treatment programme', Punishment \& Society 2019, 1, p. 107-124.

27 V. de Vogel e.a., Female Additional Manual (FAM). Additional guidelines to the HCR-20 for assessing risk for violence in women, Utrecht: Van der Hoeven Stichting 2012.

28 M. Steketee e.a., Preventie van intergenerationeel geweld in Nederland en EU. Verkenning van wat werkt, Atria: Kennisinstituut voor Emancipatie en Vrouwengeschiedenis/Utrecht: Verweij-Jonker Instituut 2016. 
wacht dat zij deze vorm van geweld aanpakt en maatregelen neemt om geweld tegen vrouwen te voorkomen, de slachtoffers te beschermen en de daders te vervolgen. Aandacht voor 'gendered' geweld is onder andere terug te zien in het emancipatiebeleid 2018-2021 van het ministerie van Onderwijs, Cultuur en Wetenschap, waarin het kabinet streeft naar sociale veiligheid voor alle burgers, met de nadruk op vermindering van intimidatie en (seksueel) geweld tegen vrouwen, waarbij mannen, die vaker dader zijn dan vrouwen, een deel van de oplossing moeten zijn. ${ }^{30}$ De voorbeelden geven aan hoe sterk verankerd de veronderstellingen zijn omtrent de genderverhoudingen met geweld. Dit kan zelfs doorwerken in de manier waarop cijfers over geweld verzameld worden en zo stereotypering versterken. ${ }^{31}$ Of anders gezegd: gendersensitief beleid loopt het risico evenzo genderstereotypen te reproduceren als beleid dat zich genderneutraal opstelt en geen oog voor de genderrelaties heeft.

\section{Tot slot: gender en weerbaarheid tegen geweld}

Geweld is een complex fenomeen, en geweldservaringen zijn, zoals we hebben beschreven, niet symmetrisch, maar tegelijk heeft dit inzicht een enorme stereotypering van mannelijkheid en vrouwelijkheid in verband met daderschap en slachtofferschap versterkt. Geweld structureel aanpakken betekent dus met deze complexiteit rekening houden. Weerbaarheid tegen geweld - in de zin dat professionals in staat zijn om moeilijke zaken aan te pakken en niet bezwijken omdat ze niet goed raad weten met de complexiteit van gewelddadige casuïstiek en zich overvraagd voelen - kan alleen worden verhoogd als we de bestaande categorisering en genderstereotiepe patronen niet zomaar klakkeloos toepassen in de poging geweld te begrijpen en adequaat te bejegenen. Bovendien moeten we alert blijven op andere verhoudingen van sociale ongelijkheid die ook van invloed zijn op geweldservaringen. Dit geldt op het niveau van onderzoek, maar met name ook voor professionals in hun analyse en reactie op geweldservaringen. Want een weerbare professional is een professional die oog heeft voor de complexiteit van de aan te pakken problemen en alert is op het ontstaan van vooroordelen en makkelijke stereotypen. Op het eerste gezicht lijken die nuances waar wij hier aandacht voor hebben gevraagd het werk van de professional niet eenvoudiger te maken. Maar wie werkelijk iets wil betekenen voor mensen die met gewelddadige ervaringen in hun leven te maken krijgen, kan het zich eenvoudigweg niet permitteren de zaken eenvoudiger voor te stellen dan ze zijn. Een weerbare professional kan zich dat niet permitteren.

30 Kamerbrief 29 maart 2018 over de Emancipatienota 2018-2021. www.rijksoverheid.nl/ documenten/kamerstukken/2018/03/29/emancipatienota-2018-2021.

31 S. Walby e.a., The concept and measurement of violence against women and men, Bristol: Policy Press 2017. 